\title{
Study on the Differences in English and Chinese Language and Cultural Background from the Perspective of Comparison of English and Chinese Proverbs
}

\author{
Junxiang $\mathrm{Li}^{1}$ \\ ${ }^{1}$ Ningbo City College of Vocational Technology, Ningbo, Zhejiang, 315100
}

Keywords: Proverbs; Cultural background; Comparison

\begin{abstract}
This paper starts with the differences in the expression of English and Chinese proverbs, analyzes them in depth, and summarizes the great cultural differences between the two cultures in English and Chinese, including historical background, geographical environment, customs, and psychological quality. However, English and Chinese proverbs can be translated into each other, and the proverbs in both languages are also very rich.
\end{abstract}

\section{Introduction}

Language is the carrier of culture, a tool for disseminating and exchanging culture, and it is also an important part of cultural composition. Proverbs are a very vivid and interesting part of a nation's language. It is a fixed sentence that people often use to summarize the experience and lessons learned in labor life and social activities with simple words. In a long history, proverbs have been tempered and used various expression methods and rhetorical devices to form language idioms, metaphors, philosophies, inscriptions, and popular idioms. The famous British philosopher, Francis Bacon, once said. The characteristics, wisdom and spirit of a nation can all be found in the ethnic proverbs. To some extent, proverbs reflect the material and social life of a nation. Its formation and application have a close relationship with a nation's historical background, geographical environment, customs, psychological quality and religious beliefs, so it can reflect a nation's language and cultural characteristics. Analyzing and comparing the characteristics of English-Chinese and Chinese-language proverbs can help us understand the differences between Chinese and English language and cultural backgrounds, so that when we use English-Chinese language communication, we can make use of appropriate language to successfully achieve cross-cultural communication. This article only discusses the different cultural backgrounds reflected by the characteristics of English and Chinese.

\section{Different Historical Backgrounds}

The United Kingdom was the first country in human history to carry out the capitalist industrial revolution. In the early stages of capitalist development, it experienced the "enjoy man" enclosure movement, and the class exploitation was severely oppressed. As a result, many English proverbs reflected oppression. The prosecution and condemnation of the exploiting class, for example:

The king and pope, the line and wolf.

The king and pope are lions and wolves.

The pleasure of the mighty is the tears of the poor.

The rich are indulging in the wild, and the poor tears into the river.

Compared with the feudal society, capitalist society is a tremendous advancement of human society. The rapid development of productive forces has created a more splendid material civilization than feudal society. People worship money and make money, but at the same time realize the importance of commodity trade. It is reflected in English slang, for example,

Money can buy the devil himself. Money can buy ghosts.

Money is the best lawyer. Money is the best lawyer.

On the other hand, after the capitalist Renaissance movement, people's thoughts were greatly 
liberated. They recognized the importance of educational scientific knowledge. People have a strong desire for freedom and equality. There are many slang expressions in English, such as:

Better be a free bird, then a captive king.

It is better to be a free bird than a prisoner.

Freedom and liberty are better worth than all the gold of the world.

Freedom and liberation surpass all the world's gold.

China has gone through thousands of years of feudal society. The ruling class is like a tiger. People are suffering from exploitation and oppression and live in dire straits. Chinese slang is reflected in many aspects such as:

oppressive rule.

One person got the dog to heaven.

\section{Different Geographical Environment}

The United Kingdom is an island nation and the fourth is facing the sea. Since ancient times, people have attached importance to marine fishing, agriculture and animal husbandry. This is closely related to the climate. Therefore, many proverbs reflect it, such as:

He goes a great voyage that goes to the bottom of the sea.

The person who reached the bottom of the sea really did a voyage.

God helps the sailor, but he must rows.

God bless sailors, but sailors have to row by themselves.

Third, reflect different customs

Life is the source of proverbs. Customs and customs have a great influence on proverbs. In turn, proverbs reflect the style of a country's customs and habits. For example:

Love me love my dog.

Love me and love my dog.

A good dog deserves a good bone.

Good dogs should have good bones.

The British use dogs to watch or hunt, they also play animals, and they regard the dog as a person's partner and pet. Therefore, they generally do not feel disgusted with the dog and have a lot of love and pity. In China, the dog is the first animal to watch. Although the Chinese people like the dog's certain qualities, such as the faithfulness and bravery of the dog, the dog often reminds people of something that is repulsive, such as:

The dog bites the dog.

Dogs bark.

Thinking is shared by all mankind. The language accompanying the shadow of thinking has strong national characteristics. In English and Chinese languages, English and Chinese proverbs of different forms can carry information of the same or similar meaning. It can be seen that each reflects the cultural life customs.

Fourth, reflect the different psychological qualities

All ethnic groups have different ways of understanding the world and transforming the world. Therefore, they form their own unique psychological qualities. The difference in psychological quality is an important feature distinguishing ethnic groups. The psychological qualities of different ethnic groups form different cultural characteristics, and thus can be seen from words. Corresponding psychological qualities such as:

An English man is never happy but when he is miserable, a Scotchman never at home but when he is abroad and an Irishman never at peace but when he is fighting.

The English people will only feel happy when they are struggling. The Scots only feel comfortable when they are away from home. The Irish people only feel peaceful when fighting. This idiom is not without humor to show the different personalities of the three British people.

A fence of three piles, a hero three.

The former people planted trees to cool down.

The above proverbs reflect the spirit of mutual aid, friendship, and kindness. 
The same word "candle", used differently in English and Chinese proverbs, shows the differences in people's understanding of the objective world under different cultural backgrounds. For example:

You cannot burn the candle at both ends.

Candles can't be two points.

This slang metaphor people can not spend too much effort on money, or do two opposite things at the same time, "candle" in this word, contains a relatively light national culture.

Spring silkworms die to dead silk, and the wax torch turns into tears. The candles in this proverb and the candle's tears of a candle are endlessly flowing. The leisurely thoughts, the lingering loveliness, and the eager and earnest affection are full of words and expressions that express the lover's deep thoughts and love, and their death. With the determination and conviction of repentance, the word "candle" is once again given humanity and cast a deeper national culture.

Although English and Chinese have different cultural backgrounds, the cultural information carried by both English and Chinese can be expressed in another language. Therefore, English and Chinese can be translated into each other, which also deepens the exchanges between different ethnic groups. Fusion. There is a wide range of differences between English and Chinese languages and cultural backgrounds, and there are also numerous proverbs in both languages.

\section{References}

[1] Li Yongfang, Second Edition of the English-Chinese Sentence Dictionary of English Proverbs [M], Shanghai: Shanghai Foreign Language Education Press, 2009

[2] Li Yanlin, English Cultural Translation Practice Course [M], Changsha: Central South University Press, 2006

[3] Ping Hong, English idioms and British and American cultures [M], Beijing: Foreign Language Teaching and Research Press, 2000. 